\title{
On the propagation limits and speeds of premixed cool flames at
}

\section{elevated pressures}

\author{
Yiguang $\mathrm{Ju}^{*}$
}

\begin{abstract}
The flame speeds and propagation limits of premixed cool flames at elevated pressures are numerically modelled using dimethyl ether mixtures. The primary focus is paid on the effects of pressure, mixture dilution, computation domain, and heat loss on cool flame propagation. The results showed that cool flames exist on both fuel lean and fuel rich sides and dramatically extend the lean and rich flammability limits of conventional hot flames. There exist three different flame regimes: the hot flames, lean and rich cool flames, and double flames. A new flame flammability diagram including both cool flames and hot flames at elevated pressures is obtained. The results show that pressure significantly changes cool flame propagation and burning limits. It is found that the increase of pressure affects the propagation speeds of lean and rich cool flames differently due to the negative temperature coefficient effect. On the lean side, the increase of pressure accelerates the cool flame chemistry and shifts the transition limit of cool flame to hot flame to a lower equivalence ratio. At lower pressure, there is an extinction transition from hot flame to cool flame. However, above a critical pressure, the hot flame directly transfers to a cool flame without hot flame extinction. Moreover, increases in dilution reduce the heat release of the hot flame and promote cool flame formation. Furthermore, the results show that a smaller downstream computation domain and higher heat loss also extend the cool flame transition limit and promote cool flame formation.
\end{abstract}


Keywords: Cool flames, high pressure, dilution, heat loss, flammability limit, flame speed

\section{Introduction}

The study of cool flames has received renewed interest due to the need for knocking control in advanced engines $[1,2]$ and the recent observations of cool flames in microgravity [3-5] and plasma assisted low temperature combustion [5-8]. Although cool flames were discovered two centuries ago $[9,10]$, many fundamental flame properties such as the flammability limit and flame speeds of cool flames, especially at high pressures and with mixture dilution, remain unknown. The main challenge in studying the dynamics of cool flames originates from the difficulty to create a stable cool flame experimentally. Efforts of previous cool flame studies have been focused on using heated surfaces and heated burners [11-13], jet stirred reactors [14], heated flow reactors $[15,16]$, rapid compression machines [17], counterflow flames [5, 6, 18-21], propagating flames [7, 22], and droplets [3, 4, 23]. Unfortunately, since many of these studies were either limited by the intermittency of cool flames or strongly affected by the flame wall thermal and chemical interaction, few studies have been made on effects of pressure, heat loss, mixture dilution, and chemistry-transport coupling on the propagation limits and speeds of cool flames. Recent counterflow cool flame studies $[18,24,25]$ using ozone sensitization to enhance the low temperature chemistry have provided some quantitative experimental data of the extinction limits and structures of diffusion and premixed cool flames. It was observed experimentally that a cool flame can be sustained beyond the extinction limit of a hot flame. However, few direct measurements of cool flame propagation speed and flammability limits were attempted in the above studies for fuel/air mixtures.

Recently, in modeling high pressure sparked assisted homogeneous charge compression ignition (HCCI) using a lean premixed n-heptane/air mixture [2], it was found that a spark initiated outwardly propagating hot flame eventually transferred into a double flame structure, 
consisting a high temperature flame (hot flame) and a cool flame. Nevertheless, it was not clear whether the observed premixed cool flame only existed under transient conditions. A recent numerical study of freely propagating dimethyl ether flames revealed that steady cool flame can exist at fuel lean conditions beyond the flammability limit of hot flames [7, 26]. More recently, a double flame structure was observed in a counterflow flame [25]. However, these studies were limited to atmospheric pressure or stretched flames and did not examine the fundamental properties of flammability limit and flame speed and the effects of computation domain, heat loss, and mixture dilution on cool flames. Although Fairlie et al. [27] measured the cool flame speed in a propane-oxygen mixture at different pressures, the mixture temperature was very high $(590 \mathrm{~K})$ so that the residence time of the heated mixture was comparable to the auto-ignition time. Therefore, the measured flame speed might be caused by auto-ignition rather than flame propagation. As such, it is not clear how pressure, mixture dilution, heat loss, and computational domain will affect the fundamental properties of premixed cool flames at high pressure.

The goal of this study is to simulate numerically the fundamental properties of premixed cool flames at high pressure. Specifically, the impact of pressure, mixture dilution, heat loss, and computation domain on the propagation limits and speeds of dimethyl ether premixed cool flames is examined using a detailed kinetic mechanism. First, the cool flame propagation speeds, structures, and flammability limits of dimethyl ether/air mixtures are studied at pressures up to $20 \mathrm{~atm}$. Then, the key reaction pathways for lean and rich cool flames at different pressures and fuel concentrations are analyzed. A generic flammability limit diagram for both hot and cool flames at elevated pressure is presented. Furthermore, the effects of computation domain, initial temperature, heat loss, and mixture dilution on cool flame propagation speeds and the transition limits from cool flame to hot flame are examined. Finally, conclusions are made. 


\section{Numerical Models}

In this study, we consider the one-dimensional, steady-state, freely-propagating premixed flame for the simulations of the flame speeds and the flammability limits of cool flames and hot flames. To compute a steady state flame structure, the flame front is anchored at $\mathrm{X}=0.075 \mathrm{~cm}$ by fixing its temperature at $608 \mathrm{~K}$. Note that the selection of $608 \mathrm{~K}$ is arbitrary. It only serves to fix the flame front location and does not affect the simulation results. The upstream inlet boundary is varied from $X=-2 \mathrm{~cm}$ to $-20 \mathrm{~cm}$. All species concentrations and the initial temperature are fixed at the upstream boundary. The downstream computation domain size is also varied from $1.5 \mathrm{~cm}$ to $10 \mathrm{~cm}$. The zero-gradient conditions are imposed at the downstream boundary.

Dimethyl ether (DME) is chosen as the fuel in this study because it has strong low temperature chemistry and has been widely studied and validated [28-30]. Comparisons between a recent DME model by Kurimoto et al.[29] modified from Zhao et al. [28] and the model by Burke et al. [30] for ignition delay time at $10 \mathrm{~atm}$ were made. These mechanisms predicted similar ignition delay time at high pressure. However, the Burke et al. model is very computationally stiff and has not been well validated for flame speeds at high pressures. On the other hand, the models by Zhao et al. [28] and Kurimoto et al. [29] have been validated against flame speeds at elevated pressures [31] as well as for cool flame extinction [18]. The major difference between Zhao's model [28] and Kurimoto's model [29] is that Kurimoto's model has an update of the $\mathrm{C}_{1}$ chemistry, DME dissociation reaction rate [31], and the increase of the branching ratio of $\mathrm{QOOH}$ dissociation over $\mathrm{O}_{2} \mathrm{QOOH}$ formation from $\mathrm{RO}_{2}$ in order to lower the over prediction of fuel oxidation and $\mathrm{CO}$ formation at low temperature (550-650 K) in the atmospheric flow reactor experiment [29]. Thus, we chose the DME model by Kurimoto et al. in this study.

In order to study the effect of mixture dilution on cool flames, we used mixtures of $\mathrm{DME} /\left[(1-x) \mathrm{O}_{2}+x \mathrm{~N}_{2}\right]$. The nitrogen mole fraction $(x)$ in the oxidizer mixture is varied from 
0.79 to 0.90 to mimic the change from air to a highly diluted oxidizer stream. To examine the

effect of pressure, the mixture pressure is increased from 1 to $20 \mathrm{~atm}$. The initial temperature is varied from $300 \mathrm{~K}$ to $550 \mathrm{~K}$, which is below the onset temperature of the low temperature fuel oxidation window at the interested flow residence time. As shown later, since the decrease of initial mixture temperature only decreases the cool flame speed, unless otherwise stated we only discuss the results of 530K here. The effects of temperature on cool flames at 1 atm was discussed in [7]. The results showed that with the decrease of initial mixture temperature from $550 \mathrm{~K}$, the cool flame speed decreases. At $300 \mathrm{~K}$, the cool flame speed became so small that it failed to propapgate when radiative heat loss was considered. In the radiation calculation, we used the optically thin radiation model for simplicity. The Planck mean absorption coefficients are calculated for $\mathrm{CH}_{4}, \mathrm{CO}_{2}, \mathrm{H}_{2} \mathrm{O}$, and $\mathrm{CO}$ using the statistical narrow-band model found in [32]. In order to see how heat loss affects of cool flame dynamics, the magnitude of radiation heat loss is varied for comparison. The governing equations are solved by using a revised version of the Chemkin III code with an arc-length continuation method [32]. The flame speed is solved as an eigenvalue problem by introducing another fixed temperature on the flame temperature profile as an internal boundary. All computational conditions are listed in Table 1. In this study, our focus is placed only on the steady state flame dynamics although some unsteady cool flame dynamics for diffusion cool flames were reported in our recent publication [33].

\begin{tabular}{|l|l|l|l|l|l|}
\hline $\begin{array}{l}\text { Pressure, } \\
\text { atm }\end{array}$ & $\begin{array}{l}\text { Initial mixture } \\
\text { temperature, K }\end{array}$ & $\begin{array}{l}\text { Equivalence } \\
\text { ratio }\end{array}$ & $\begin{array}{l}\text { Nitrogen } \\
\text { dilution }\end{array}$ & $\begin{array}{l}\text { Upstream } \\
\text { computation } \\
\text { domain size, cm } \mathrm{cm}\end{array}$ & $\begin{array}{l}\text { Downstream } \\
\text { computation domain } \\
\text { size, cm }\end{array}$ \\
\hline $1-20$ & $300-550$ & $0.2-100$ & $79-90 \%$ & $2-20$ & $1.5-10$ \\
\hline
\end{tabular}

Table 1 Computation conditions of DME/[(1-x) $\left.\mathrm{O}_{2}+x \mathrm{~N}_{2}\right]$ flames in the present study.

\section{Results and Discussions}

\subsection{Effect of pressure on cool flames}


To illustrate the dynamics of cool flames at lower computational cost, in this section the downstream computation boundary is fixed at $1.5 \mathrm{~cm}$ unless otherwise stated. The effects of upstream and downstream computational domain on the results will be discussed in the next section. Figure 1 shows the dependence of flame temperature on equivalence ratio $(\Phi)$ for DME/air mixtures at pressure of 2 atm. Fig. 1 shows that there are three different flame regimes, the hot flame, cool flame, and double flame. Firstly, the hot flame regime $(A B C)$ exists only at high temperature. Points $A$ and $C$ denote, respectively, the lean and the rich flammability limits of hot flames. Secondly, there are two different cool flame branches, a lean cool flame $(E F)$ and a rich cool flame $(C D)$. The lean cool flame temperature on the fuel lean side is lower than that of the rich cool flame on rich side $(C D)$ unless the equivalence ratio is greater than 20. Thirdly, on the fuel lean side, between the hot flame $(A B)$ and the cool flame branch $(E F)$ there is a third flame branch $A E$, the so called double flame branch, in which a leading cool flame front is followed by a decoupled reaction zone of intermediate temperature $\left(\mathrm{H}_{2} \mathrm{O}_{2}\right.$ decomposition to $\left.\mathrm{OH}\right)$ [7, 20]. Here, point $E$ in Fig.1 represents the transition limit from cool flame to hot flame, beyond which a lean cool flame does not exist.

Figs.2a and $2 \mathrm{~b}$, respectively, show the distributions of temperature and species mole fractions of the three different flame regimes at the same equivalence ratio (marked by circles in Fig.1). Fig.2a shows that the lean hot flame has a peak temperature about 1900K, while the lean cool flame only has a flame temperature at $750 \mathrm{~K}$. On the other hand, the double flame has two separated temperature rises, one at cool flame front $(X=0.075 \mathrm{~cm})$ and the other at the reaction zone of $\mathrm{H}_{2} \mathrm{O}_{2}$ decomposition $\left(\mathrm{H}_{2} \mathrm{O}_{2}=2 \mathrm{OH}\right)$ near at=1.4 cm. For the hot flame, Fig. $2 \mathrm{~b}$ shows that both the fuel and $\mathrm{CH}_{2} \mathrm{O}$ formed in the preheat zone are completely oxidized to the product. For the cool flame, however, only half of the fuel is consumed and converted to $\mathrm{CH}_{2} \mathrm{O}$ and other intermediate species. For the double flame, the leading cool flame structure is the same as that of the cool flame, but all the fuel and $\mathrm{CH}_{2} \mathrm{O}$ are oxidized into $\mathrm{CO}$ and $\mathrm{H}_{2} \mathrm{O}$ in the reaction zone of $\mathrm{H}_{2} \mathrm{O}_{2}$ decomposition to $\mathrm{OH}$. The similarity in the structures of cool flame 
and double flame indicates that the two reaction zones in the double flame are isolated and its flame structure is counter intuitive, its existence was already observed experimentally in our recent study [25] and also was found in a previous transient simulation of $n$-heptane ignition [2]. The existence of double flame is a result of competition of the heat loss, residence time, and the reaction time of $\mathrm{H}_{2} \mathrm{O}_{2}$ decomposition. The effects of heat loss and residence time on the existence of cool flame and double flame will be discussed in the following section. Note that the temperature of the cool flame still slightly increases as it approaches the downstream computation domain. This is because the low temperature chemistry is still evolving unless there is enough heat loss to quench it. Therefore, the reaction zone of the intermediate temperature will be affected by the downstream computation domain. This will be further discussed in the next section.

The experience of classical laminar flame dynamics tells us that flames on the upper (the hot flame) and the lower (the cool flame) branches in Fig.1 are stable if they are away from the extinction limits. On the other hand, flames on the middle branch (the double flame) are unstable. To confirm this point, we made a preliminary unsteady simulation for the lean cool flame in Fig. $2 \mathrm{a}(\Phi=0.6$ and $\mathrm{P}=2 \mathrm{~atm})$. The initial flame temperature of the steady state solution was perturbed by $5 \mathrm{~K}$. Figure $2 \mathrm{c}$ shows the time history of the peak flame temperature of the unsteady simulation (with time step of one micro-second). It is seen that after the initial evolution, the lean cool flame became stable. This result confirms the estimate of the flame stability from the classical flame dynamics. Of course, flame stability analyses at all simulated conditions require effort in future studies. It should be noted that although the middle branch of the double flame may unstable for freely-propagating flames, when subject to a heat loss or limited burning zone, a stable double flame structure may exist. In fact, a stable double flame structure was observed in a recent counterflow experiment $[18,25]$. 
For fuel rich flames, unlike the lean flames, Fig.1 shows that the transition from hot flame to cool flame occurs smoothly without an extinction (direct transition). In order to demonstrate that the cool flame on the rich side is indeed governed by low temperature chemistry even though its peak temperature can be over than $1200 \mathrm{~K}$, Figs.3a and 3b show the temperature and species distributions as well as the flame speed sensitivity of the rich cool flame at equivalence ratio of 5. Fig.3a shows that there is a rapid rise of temperature, $\mathrm{CH}_{2} \mathrm{O}$, $\mathrm{H}_{2} \mathrm{O}_{2}$, and $\mathrm{RO}_{2}$ in the at the leading cool flame reaction zone $(X \approx 0.1 \mathrm{~cm})$. Following the reaction zone of the cool flame, there is an intermediate temperature reaction zone $(X \approx 0.2 \mathrm{~cm})$, at which $\mathrm{OH}$ is formed by $\mathrm{H}_{2} \mathrm{O}_{2}$ decomposition and $\mathrm{CH}_{2} \mathrm{O}$ is oxidized into $\mathrm{CO}$. Therefore, the rich cool flame has a double reaction zone structure. This will be more clearly shown in the following section. Due to the lack of oxygen in the fuel rich condition, $\mathrm{CO}$ is not oxidized to $\mathrm{CO}_{2}$. Therefore, the rich cool flame structure is essentially a coupled double flame structure led by a cool flame. To demonstrate that it is the low temperature chemistry which governs the propagation of the rich cool flame, Fig.3b compares the flame speed sensitivity of reactions, respectively, at equivalence ratio $(\Phi)$ of 1,5 and 10 . It is seen that at $\Phi=1$, $\mathrm{H}+\mathrm{O}_{2}=\mathrm{OH}+\mathrm{O}$ and $\mathrm{CO}+\mathrm{OH}=\mathrm{CO}_{2}+\mathrm{H}$ reactions are the dominant chain branching and propagation reactions, indicating that the hot flame is governed by the high temperature chemistry. However, at $\Phi=5$, neither the above two reactions play any key role in flame propagation. Instead, the low temperature reactions such as $\mathrm{CH}_{3} \mathrm{OCH}_{2} \mathrm{O}_{2} \rightarrow \mathrm{CH}_{2} \mathrm{OCH}_{2} \mathrm{OOH}$ ( $\mathrm{RO}_{2}$ isomerization to QOOH), $\mathrm{CH}_{2} \mathrm{OCH}_{2} \mathrm{OOH} \rightarrow \mathrm{OH}+2 \mathrm{CH}_{2} \mathrm{O}$ (QOOH decomposition), and $\mathrm{CH}_{2} \mathrm{OCH}_{2} \mathrm{O}_{2} \mathrm{H}+\mathrm{O}_{2} \rightarrow \mathrm{O}_{2} \mathrm{CH}_{2} \mathrm{OCH}_{2} \mathrm{O}_{2} \mathrm{H}$ (the second $\mathrm{O}_{2}$ addition) play the dominant role in flame propagation. Therefore, even the final flame temperature is higher than the cross-over temperature of $\mathrm{H}+\mathrm{O}_{2}=\mathrm{OH}+\mathrm{O}$, because of the lack of oxygen after the cool flame front to further oxidize the $\mathrm{CO}$, the flame propagation is still governed by the cool flame chemistry at the leading cool flame front and the subsequent $\mathrm{H}_{2} \mathrm{O}_{2}$ reaction kinetics. Numerical results also 
show that as the equivalence ratio further increases to 20 or higher the reactions of $\mathrm{H}_{2} \mathrm{O}_{2}$ decomposition and $\mathrm{CH}_{2} \mathrm{O}$ oxidation are suppressed and only the cool flame front remains.

The effect of pressure on the flame temperatures and flammable regions of different flame regimes is plotted in Fig. $4 \mathrm{~b}$. Note that the flame temperature of hot and cool flames on the rich side is only slightly affected by pressure. However, the cool flame and its transition limit to hot flame $(E)$ on the fuel lean side are significantly changed by the increase of pressure. It is seen that as the pressure decreases from 2 to $1 \mathrm{~atm}$, the flammable region of cool flame on the lean side extends dramatically to the fuel rich side. At 1 atm, the transition limit of cool flame to hot flame moves even to the fuel rich side $(\Phi=6.5)$, leading an extended flammable region of cool flames. On the other hand, with the increase of pressure, the cool flame temperature increases and the flammable region of the cool flame on the fuel lean side narrows dramatically. This is because the rise of pressure results in an increase of the chemical heat release rate over the radiative heat loss and leads to a faster transition to hot flame. At the 4 atm, Fig.4a shows that the cool flame to hot flame transition limit reduces to $\Phi=0.43$, which is close to the flammability limit of hot flame $(A)(\Phi=0.30)$. As the pressure further increases to $20 \mathrm{~atm}$, it is found that the cool flame to hot flame transition limit $(E)$ merges with the lean flammability limit of hot flame $(A)$, leading to a direct transition from hot flame to cool flame (similar to that on fuel rich side) without an extinction limit (see Figs.4a and $4 \mathrm{~b}$ ). This finding implies that at lower pressure, due to large ratio of radiation heat loss to chemical heat release, there exists an extinction transition from the hot flame to the cool flame. However, at higher pressure, the increase of low temperature reactivity and reduction of the ratio of the radiation heat loss to chemical heat release lead to a direct transition between cool flame and hot flame. This result has a direct implication in high pressure turbulent combustion of a stratified flow such as the partially premixed combustion engines. This is because the cool flame chemistry timescale is very short at high pressure. Moreover, the cool flame speed increases with mixture temperature. As such, in both fuel lean 
and rich regions, cool flames can be formed. The turbulent transport and the variation of temperature may cause transitions between hot flames and cool flames as well as hot ignition and low temperature ignition.

Fig. $4 \mathrm{~b}$ shows the flame speed dependence on equivalence ratio and pressure corresponding to Fig.4a. At 2 atm, it is seen that the flame speed of hot flame branch $(A B C)$ decreases rapidly as the flame approaches to its lean $(A)$ and rich $(C)$ flammability limits. However, the flame speeds of the cool flames on both fuel lean $(E F)$ and rich $(C D)$ sides only weakly depends on the equivalence ratio.

To clarify above discussions, Fig.5 shows the pressure dependence of normalized flame temperatures and flame speeds by their values at $1 \mathrm{~atm}$ for the hot flames as well as the lean and rich cool flames. It is seen that the flame temperatures of hot flame and rich cool flame only have negligible dependence on pressure. However, the lean cool flame temperature increases considerably with pressure. The normalized flame speeds of hot flame and lean cool flame both decrease with pressure despite of their significant difference in pressure dependences of high temperature chemistry and low temperature chemistry. In a global reaction, the flame speed depends on pressure in a power law of reactive order and diffusivity, $\mathrm{p}^{n / 2-1}$, where $n$ is the overall reaction order. However, the cool flame chemistry has a strong pressure dependence due to the unimolecular reactions such as $\mathrm{RO}_{2}$ isomerization as well as QOOH and $\mathrm{O}_{2} \mathrm{QOOH}$ decomposition. An increase of pressure will enhance the low temperature reactivity and increases the cool flame speed. Nevertheless, contrary to our intuitive thinking, the lean cool flame speed decreases rapidly with pressure. In fact, this rapid decrease is caused by the negative temperature coefficient (NTC) effect. An increase of lean cool flame temperature with pressure will slow down the low temperature reactivity. This is one of the interesting findings of cool flame characteristics. The pressure dependence of the rich cool flame speed is very different from that of the lean cool flame. This is because unlike the lean cool flames, with the increase of pressure the flame temperature change of the rich 
cool flame is negligible. Thus, it does not have the NTC effect to reduce the low tempreautre reactivity. On the other hand, the increase of pressure will increase the low temperature reactivity via unimolecular dissociation. As a result, the flame speed of rich cool flame is much less affected by the pressure increase. This is another increasing characteristics of cool flames. Therefore, at high pressure, the dynamics of rich cool flames may be more important than lean cool flames because of its weaker dependence on pressure or increasing mass burning rate with pressure.

To demonstrate how pressure increase changes the cool flame structures, the lean cool flame structure of DME/air at $20 \mathrm{~atm}$ is plotted in Fig.6. It is seen that at high pressure, similar to the rich cool flame, lean cool flames have a coupled double reaction zone structure. The intermediate species such as $\mathrm{H}_{2} \mathrm{O}_{2}$ and $\mathrm{CH}_{2} \mathrm{O}$ formed in the leading cool flame are oxidized immediately into $\mathrm{CO}$ via $\mathrm{OH}$ production by $\mathrm{H}_{2} \mathrm{O}_{2}$ decomposition. After the reaction zone of $\mathrm{H}_{2} \mathrm{O}_{2}$ decomposition, thermal radiation reduces the temperature and no hot flame can be sustained. The coupled double flame structure for lean cool flames at high pressure demonstrates clearly the mechanism of the direct transition from hot flame to cool flame at high pressure (Fig.4a and 4b).

The effect of pressure on the flame speed sensitivity to elementary reactions of lean cool flames is plotted in Fig. 7 at $\Phi=0.2$ for $\mathrm{P}=1 \mathrm{~atm}$ and $20 \mathrm{~atm}$, respectively. It is seen that at both pressures, lean cool flame propagation is governed by low temperature reaction pathways via DME to $\mathrm{CH}_{3} \mathrm{OCH}_{2} \rightarrow \mathrm{CH}_{3} \mathrm{OCH}_{2} \mathrm{O}_{2} \rightarrow \mathrm{CH}_{2} \mathrm{OCH}_{2} \mathrm{OOH}$ reaction channels. Pressure has a significant impact on low temperature reaction kinetics. At higher pressure, $\mathrm{RO}_{2}, \mathrm{QOOH}$, and $\mathrm{O}_{2} \mathrm{QOOH}$ reaction pathways become much more important. Moreover, $\mathrm{HO}_{2}$ and $\mathrm{H}_{2} \mathrm{O}_{2}$ reaction kinetics also increases with pressure. Therefore, although the lean cool flame has a coupled double reaction zone structure (Fig.6), only the leading cool flame front governs the speed of flame propagation. This phenomenon is similar to that of the rich cool flames. 
To provide a generic understanding the flammability limits involving both cool flame

and hot flame, the dependence of the propagation limits on the equivalence ratio is plotted in Fig.8. The K-shaped flammability limit diagram at elevated pressure demonstrates that the lean flammability limit of cool flames $(D E)$ are much lower than that of hot flames $(A B)$. Therefore, high pressure cool flames extend the flammability limit of hot flames. As discussed in Fig.4a, the cool flame to hot flame transition limit $(A C)$ is strongly dependent on pressure and the ratio of heat loss to heat release rate. As the pressure increases, the cool flame to hot flame transition limit shifts to a lower equivalence ratio due to the decrease of the ratio of the radiation heat loss to cool flame heat release. At a critical equivalence ratio $(A)$, the cool flame to hot flame transition limit merges with the flammability limit of hot flame, above which the flammability limit of hot flame does not exist and is replaced by the flammability limit of cool flames at higher pressure. In the region between $A C$ and $A B$, all of the three different flame regimes, cool flame, double flame, and hot flame can exist. Note that the flame regime boundary $(A C)$ can be quantitatively affected by heat loss and also flame size (computation domain). Nevertheless, the K-shaped flammability diagram in Fig.8, for the first time, provides a qualitative picture of the flammability limits of a fuel with low temperature chemistry at high pressure.

\subsection{Effect of computation domain, heat loss, and initial temperature on cool flames}

Most of the results presented above were computed with a computational domain of $3.5 \mathrm{~cm}(\mathrm{X}=-2 \mathrm{~cm}$ to $1.5 \mathrm{~cm})$ and the cool flame size is about $1.5 \mathrm{~cm}$. The initial mixture temperature is also fixed at $530 \mathrm{~K}$. The question to ask here is how the computational domain (cool flame size), heat loss, and initial temperature affect the results quantitatively. To examine this effect, in this study the downstream computation domain is extended from $\mathrm{x}=1.5$ $\mathrm{cm}$ to $10 \mathrm{~cm}$, the upstream computation domain is extended from $\mathrm{X}=-2 \mathrm{~cm}$ to $-20 \mathrm{~cm}$, the radiation heat loss is varied by a factor of five, and the initial temperature is reduced from 550 
$\mathrm{K}$ to $420 \mathrm{~K}$. Note that we did not conduct simulations at higher temperature because the cool flame at high temperature may be subject to auto-ignition effect.

Fig.9 shows the effect of the downstream computational domain (flame size) on the computed flame temperature for all three flame regimes at $2 \mathrm{~atm}$. It is seen that the computational domain does affect the transition limit of the cool flame to hot flame, but has negligible effect on high pressure lean cool flames, hot flame, and rich cool flame because their flame thicknesses are less than $1 \mathrm{~cm}$ (Figs.3 and Fig.6). The reason why the computational domain (cool flame size) affects the transition limit of cool flame to hot flame $(E)$ is that the onset of $\mathrm{H}_{2} \mathrm{O}_{2}$ decomposition reaction is sensitive to the ratio of heat loss and chemical heat release rate. A smaller computational domain will reduce the cool flame size and introduce additional downstream heat loss to delay $\mathrm{H}_{2} \mathrm{O}_{2}$ decomposition and the transition from cool flame to hot flame. Fig.9 shows that by increasing the cool flame size from $1.5 \mathrm{~cm}$ to $6 \mathrm{~cm}$, the transition limit from cool flame to hot flame shifts to the fuel lean side and narrows the cool flame flammable region. However, in many combustion environments such as the counterflow flames and turbulent flames, the burned gas region is shortened by convective mixing, which may lead to extended flammable region of cool flames [18].

Fig.10a shows how the downstream computational domain size affects the transition limit from cool flame to hot flame $\left(\Phi_{\mathrm{E}}\right)$ and the flame speed of cool flame at the transition limit. It is seen that as the cool flame size (downstream computation domain) increases, both the transition limit and the cool flame speed at the transition limit decrease. However, the decrease rate becomes slower as the computation domain further increases. Therefore, the cool flame transition limit and the flame regimes are sensitive to the heat loss at the downstream.

Figure $10 \mathrm{~b}$ plots the effect of upstream computational domain size on the cool flame speeds, which are normalized, respectively, by that when the upstream computational domain size is $2 \mathrm{~cm}$, for three different pressure and fuel concentration conditions. Case I is the lean 
cool flame at the equivalence ratio of 0.19 and pressure of $2 \mathrm{~atm}$. Cases II and III are, respectively, the lean and rich cool flames at 20 atm for equivalence ratios of 0.3 and 10 . The upstream computation domain is increased from $2 \mathrm{~cm}$ to $20 \mathrm{~cm}$ for all three cases. It is seen that the cool flame speeds in all cases do not change with the increase of the upstream computation domain. This invariance implies that the cool flame speeds predicted at all three typical conditions are the eigenvalues of flame waves, not the ignition waves.

To further illustrate the self-sustained flame structures of the above three cases, the balances of volumetric heat conduction rates and chemical heat release rates for Cases I, II, and III are, respectively, shown in Fig.10c. It is seen that for all three cases, the heat conduction rates and the chemical heat release rates are well balanced and there is no chemical heat release rate in the pre-flame convection-diffusion zone. Once again, Fig.10c confirmed that the computed cool flames in the present studies are self-propagating flame waves. Furthermore, the comparison between the results of Cases I and II in Fig.10c shows distinctive flame structures for lean cool flames at low and high pressures. At low pressure (e.g. 2 atm), the lean cool flame has only a single cool flame front. However, at higher pressure, due to the increase of $\mathrm{H}_{2} \mathrm{O}_{2}$ decomposition rate, there are two chemical heat release peaks, a stronger cool flame peak followed by a smaller peak in the intermediate temperature reaction zone (mostly via $\mathrm{CH}_{2} \mathrm{O}+\mathrm{OH}=\mathrm{CO}+\mathrm{H}_{2} \mathrm{O}$ ). This is the typical double flame structure of a cool flame at high pressure. Similarly, the rich cool flame at $20 \mathrm{~atm}$ in Case III also has a double peak in the chemical heat release rate. Moreover, different from the lean cool flame, the rich cool flame remains the double flame structure at lower pressure (for example, at 1 and $2 \mathrm{~atm})$.

To understand how cool flame is sensitive to the heat loss, we artificially increased the radiation heat loss by a factor of five to mimic the heat loss effect caused by flow mixing and 
$\mathrm{CO}_{2}$ dilution. Fig.11a shows that an increase of heat loss only slightly affects the burning limit of hot flames, but significantly extends the transition limit of cool flame to hot flame to higher equivalence ratio and promotes cool flame formation. The extension of the cool flame transition limit to fuel rich side with the increase of radiation heat loss is because radiation heat loss suppresses the onset of $\mathrm{H}_{2} \mathrm{O}_{2}$ decomposition reaction for $\mathrm{OH}$ radical production. Therefore, in a combustion environment with strong thermal transport by convective mixing, a cool flame can exist in a broad region of equivalence ratio. Detailed combustion modeling needs to include cool flame chemistry.

To show how the initial temperature affects the cool flames, Fig.11b shows the dependences of cool flame temperature and speed on the initial mixture temperature (below the onset temperature of DME low temperature oxidation window around $550 \mathrm{~K}$ ). It is seen that as the initial mixture temperature decreases, both the cool flame temperature and the flame speed decrease. As the initial mixture temperature decreases to $420 \mathrm{~K}$, the cool flame speed is only $0.69 \mathrm{~cm} / \mathrm{s}$. A further decrease of initial temperature will result in a further decrease the flame speed. At $300 \mathrm{~K}$, the cool flame speed is too low to be appropriately modelled. Therefore, observation of cool flame propagation in laboratory may only be possible at an elevated temperature. Note that when the boundary temperature further increases beyond the temperature range in this study, the ignition timescale may become so short that ignition becomes dominant and the flame speed as an eigenvalue problem may not exist. This happens in homogeneous-charge compression-ignition (HCCI) engines.

\subsection{Effect of dilution on cool flames}

In many practical engine applications, fuel and air mixtures are often diluted by exhaust gas to reduce emissions and improve efficiency. To understand the impact of mixture dilution on the cool flame dynamics, in this study the DME/air mixtures are replaced by $\mathrm{DME} /\left(0.1 \mathrm{O}_{2}+0.9 \mathrm{~N}_{2}\right)$ in the simulations. Figs. $12 \mathrm{a}$ and $12 \mathrm{~b}$ plot the comparisons of flame 
temperature, flame speed, and the burning limits of hot and cool flames between DME/air and $\mathrm{DME} /\left(0.1 \mathrm{O}_{2}+0.9 \mathrm{~N}_{2}\right)$ mixtures at $2 \mathrm{~atm}$. Fig. $12 \mathrm{a}$ shows that the flame temperature of both hot and cool flames decrease significantly with $\mathrm{N}_{2}$ dilution. Moreover, due to reduction of flame temperature, the hot flame flammable region is dramatically narrowed, but the lean cool flame flammable region $(E F)$ becomes much broader and shifts even to the fuel rich side. Therefore, similar to heat loss, mixture dilution will suppress hot flame but promote cool flame formation. Fig. 12b shows that the both the propagation speeds of hot and cool flames are reduced by oxidizer dilution. Nevertheless, the impact of dilution on flame speed on hot flames is much larger than on cool flames, resulting in a broader flammable region of cool flames. Note that the $\mathrm{N}_{2}$ dilution effect studied here only represents the thermal and dilution effect of EGR. In real exhaust gas recirculation (EGR), there is an additional chemical effect through $\mathrm{CO}_{2}$ and $\mathrm{H}_{2} \mathrm{O}$ reactions and their third-body effect.

\subsection{Discussions and implication to engine applications}

The results predicted in this study provide a general picture of different flame regimes at different pressures and give a good explanation to previous numerical simulations and experimental observation of cool flames. Firstly, the predicted double flame structure of high pressure lean cool flames explained why a hot flame transferred to a double flame structure in the previous unsteady simulation in Ref. [2] and why a double flame structure was observed in the counterflow experiments $[18,25]$. It also supports the observation of separated cool flame and hot flame structure in the micro-combustor [15-16]. Secondly, the broader flammability limit of cool flames than hot flames provided an explanation to existence of the observed sub-limit premixed cool flames in a counterflow system [18, 25]. Thirdly, the predicted difference of flame speeds and flame structures in rich and lean cool flames suggest that rich cool flames are more observable in high pressure partially premixed combustion and contributes considerable heat release rate due to its higher flame speed. 
The present results also provide some implications of cool flames for engine applications. For HCCI engines [1], due to the high compression ratio and high uniformity of mixtures, mostly the low temperature ignition waves rather than the cool flames play a dominant role [34]. For RCCI engines [35], however, due to increased low temperature reactivity via the addition of an ignition enhancer, the cool flame speed will be increased and cool flames may play a greater role in RCCI engines In the partially premixed compression ignition (PPCI) and premixed compression ignition (PCI) engines [36, 37], due to the fuel stratification and multi-pulse fuel injections at the early compression stage, lean and rich cool flame regimes may play an important role. Moreover, due to the temperature rise in the compression process, transitions from cool flames to hot flames as well as from flames to ignition waves may also be important. In diesel engines, due to the high compression temperature, only the rich cool flames may play a key role in the low temperature heat release. Note that the present results only provide the flame regimes and dynamics at lower temperatures (below $530 \mathrm{~K}$ ). Future studies should address the influence of ignition on cool flames at higher temperatures.

\section{Conclusion}

The present simulations demonstrate that pressure, oxidizer dilution, flame size, and heat loss all have significant impacts on the propagation limits, speeds, and structure of cool flames as well as the transitions between cool flames and hot flames. Three different flame regimes, the hot flame, cool flame, and double flame, are identified. There are two kinds of cool flames, the lean cool flame and the rich cool flame, which exist, respectively, at fuel lean and rich conditions beyond the flammability limits of hot flames. The existence of lean and rich cool flames dramatically extends the lean and rich flammability limits of conventional 
hot flames. A K-shaped flammability limit diagram which includes both cool flame and hot

\section{Acknowledgements}

The author would like to acknowledge the grant support from the ARO W911NF-12-1-0167, NSF grant CBET-1507358, and NASA NNX16AK07G. The author also thanks to Mr. C. Reuter, Mr. Omar R. Yehia, and Dr. S.H. Won at Princeton University for extensive discussions. 


\section{References}

[1] J.E. Dec, Advanced compression-ignition engines - understanding the in-cylinder processes, Proceedings of the Combustion Institute 32 (2009) 2727-2742.

[2] Y. Ju, W. Sun, M.P. Burke, X. Gou, Z. Chen, Multi-timescale modeling of ignition and flame regimes of n-heptane-air mixtures near spark assisted homogeneous charge compression ignition conditions, Proceedings of the Combustion Institute 33 (2011) $1245-1251$.

[3] V. Nayagam, D.L. Dietrich, P.V. Ferkul, M.C. Hicks, F.A. Williams, Can cool flames support quasi-steady alkane droplet burning?, Combustion and Flame 159 (2012) 35833588 .

[4] V. Nayagam, D.L. Dietrich, M.C. Hicks, F.A. Williams, Cool-flame extinction during nalkane droplet combustion in microgravity, Combustion and Flame 162 (2015) 21402147.

[5] W. Sun, S.H. Won, Y. Ju, In situ plasma activated low temperature chemistry and the Scurve transition in DME/oxygen/helium mixture, Combustion and Flame 161 (2014) 2054-2063.

[6] S.H. Won, B. Jiang, P. Diévart, C.H. Sohn, Y. Ju, Self-sustaining n-heptane cool diffusion flames activated by ozone, Proceedings of the Combustion Institute 35 (2015) 881-888.

[7] Y. Ju, C.B. Reuter, S.H. Won, Numerical simulations of premixed cool flames of dimethyl ether/oxygen mixtures, Combustion and Flame 162 (2015) 3580-3588.

[8] Y. Ju, W. Sun, Plasma assisted combustion: Dynamics and chemistry, Progress in Energy and Combustion Science 48 (2015) 21-83.

[9] H. Davy, Some new experiments and observations on the combustion of gaseous mixtures, with an account of a method of preserving a continued light in mixtures of inflammable gases and air without flame, Philosophical Transactions of the Royal Society of London 107 (1817) 77-85.

[10] W. Perkin, LVII.- Some observations on the luminous incomplete combustion of ether and other organic bodies, Journal of the Chemical Society, Transactions 41 (1882) 363367.

[11] H.J. Emeléus, CCCXCIV.- The spectra of the phosphorescent flames of carbon disulphide and ether, Journal of the Chemical Society (Resumed) 129 (1926) 2948-2951.

[12] J. Powling, A new burner method for the determination of low burning velocities and limits of inflammability, Fuel 28 (1949) 25-28.

[13] P. Ballinger, P. Ryason. Isolated stable cool flames of hydrocarbons. In: editor^editors. Symposium (International) on Combustion; 1971: Elsevier. p. 271-277.

[14] J.F. Griffiths, T. Inomata, Oscillatory cool flames in the combustion of diethyl ether, J. Chem. Soc., Faraday Trans. 88 (1992) 3153-3158.

[15] H. Oshibe, H. Nakamura, T. Tezuka, S. Hasegawa, K. Maruta, Stabilized three-stage oxidation of DME/air mixture in a micro flow reactor with a controlled temperature profile, Combustion and Flame 157 (2010) 1572-1580.

[16] M. Hori, A. Yamamoto, H. Nakamura, T. Tezuka, S. Hasegawa, K. Maruta, Study on octane number dependence of PRF/air weak flames at 1-5 atm in a micro flow reactor with a controlled temperature profile, Combustion and Flame 159 (2012) 959-967. 
[17] W.S. Affleck, A. Fish, Knock: flame acceleration or spontaneous ignition?, Combustion and Flame 12 (1968) 243-252.

[18] S.H.W. Christopher B. Reuter, Yiguang Ju, Experimental Study of the Dynamics and Structure of Self-Sustaining Premixed Cool Flames Using a Counterflow Burner, Combustion and Flame 166 (2016) 125-132.

[19] C.K. Law, P. Zhao, NTC-affected ignition in nonpremixed counterflow, Combustion and Flame 159 (2012) 1044-1054.

[20] P. Zhao, W. Liang, S. Deng, C.K. Law, Initiation and propagation of laminar premixed cool flames, Fuel, (2015).

[21] S. Deng, P. Zhao, D. Zhu, C.K. Law, NTC-affected ignition and low-temperature flames in nonpremixed DME/air counterflow, Combustion and Flame 161 (2014) 1993-1997.

[22] F. Herrmann, B. Jochim, P. Oßwald, L. Cai, H. Pitsch, K. Kohse-Höinghaus, Experimental and numerical low-temperature oxidation study of ethanol and dimethyl ether, Combustion and Flame 161 (2014) 384-397.

[23] T. Farouk, M. Hicks, F. Dryer, Multistage oscillatory “Cool Flame” behavior for isolated alkane droplet combustion in elevated pressure microgravity condition, Proceedings of the Combustion Institute 35 (2015) 1701-1708.

[24] C.B. Reuter, M. Lee, S.H. Won, Y. Ju, Study of the Low-Temperature Reactivity of Large n-Alkanes through Cool Diffusion Flame Extinction, Combustion and Flame Submitted. (2017).

[25] S.H.W. Christopher B. Reuter, Yiguang Ju, Flame structure and ignition limit of partially premixed cool flames in a counterflow burner, Proceedings of the Combustion Institute 36 (2016).

[26] Y. Ju, C.B. Reuter. Numerical Simulations of Cool Flame Propagation Limits and Speeds at Elevated Pressures. 54th AIAA Aerospace Sciences Meeting; 2016.

[27] R. Fairlie, J. Griffiths, K. Hughes, H. Pearlman, Cool flames in space: experimental and numerical studies of propane combustion, Proceedings of the Combustion Institute 30 (2005) 1057-1064.

[28] Z. Zhao, M. Chaos, A. Kazakov, F.L. Dryer, Thermal decomposition reaction and a comprehensive kinetic model of dimethyl ether, International Journal of Chemical Kinetics 40 (2008) 1-18.

[29] N. Kurimoto, B. Brumfield, X. Yang, T. Wada, P. Diévart, G. Wysocki, Y. Ju, Quantitative measurements of $\mathrm{HO} 2 / \mathrm{H} 2 \mathrm{O} 2$ and intermediate species in low and intermediate temperature oxidation of dimethyl ether, Proceedings of the Combustion Institute 35 (2015) 457-464.

[30] U. Burke, K.P. Somers, P. O’Toole, C.M. Zinner, N. Marquet, G. Bourque, E.L. Petersen, W.K. Metcalfe, Z. Serinyel, H.J. Curran, An ignition delay and kinetic modeling study of methane, dimethyl ether, and their mixtures at high pressures, Combustion and Flame 162 (2015) 315-330.

[31] D. Liu, J. Santner, C. Togbé, D. Felsmann, J. Koppmann, A. Lackner, X. Yang, X. Shen, Y. Ju, K. Kohse-Höinghaus, Flame structure and kinetic studies of carbon dioxide-diluted dimethyl ether flames at reduced and elevated pressures, Combustion and Flame 160 (2013) 2654-2668. 
[32] Y. Ju, H. Guo, K. Maruta, F. Liu, On the extinction limit and flammability limit of nonadiabatic stretched methane-air premixed flames, Journal of fluid mechanics 342 (1997) 315-334.

[33] C.H. Sohn, H.S. Han, C.B. Reuter, Y. Ju, S.H. Won, Thermo-kinetic dynamics of nearlimit cool diffusion flames, Proceedings of the Combustion Institute, (2016).

[34] A. Krisman, E.R. Hawkes, M. Talei, A. Bhagatwala, J.H. Chen, A direct numerical simulation of cool-flame affected autoignition in diesel engine-relevant conditions, Proceedings of the Combustion Institute, (2016).

[35] D. Splitter, R. Reitz, R. Hanson, High Efficiency, Low Emissions RCCI Combustion by Use of a Fuel Additive, SAE International Journal of Fuels and Lubricants 3 (2010) 742756.

[36] G.A. Lechner, T.J. Jacobs, C.A. Chryssakis, D.N. Assanis, R.M. Siewert, Evaluation of a narrow spray cone angle, advanced injection timing strategy to achieve partially premixed compression ignition combustion in a diesel engine, Report No. 0148-7191, SAE Technical Paper, 2005.

[37] K. Okude, K. Mori, S. Shiino, T. Moriya, Premixed compression ignition (PCI) combustion for simultaneous reduction of NOx and soot in diesel engine, Report No. 0148-7191, SAE Technical Paper, 2004. 


\section{Figures and Figure Captions}

Fig.1 The dependence of flame temperature on equivalence ratio of dimethyl ether/air mixture at $2 \mathrm{~atm}$. The circles mark three different flame regimes at the same condition.

Fig.2 (a) The temperature distribution in the hot flame, double flame, and cool flame, for DME/air mixture at $\Phi=0.6$ and $\mathrm{P}=2 \mathrm{~atm}$; (b) $\mathrm{CH}_{2} \mathrm{O}$ and DME distributions in the hot flame, double flame, and cool flame, for DME/air mixture at $\Phi=0.6$ and $\mathrm{P}=2 \mathrm{~atm}$

Fig.2c The time history of the peak flame temperature of the lean cool flame at $\Phi=0.6$ and 2 atm with an initial temperature perturbation of $5 \mathrm{~K}$ from the steady state solution.

Fig.3 a) Fuel rich flame structure at equivalence ratio of 5; b) Flame speed sensitivity of flames at equivalence ratios of 1,5 , and 10 , respectively.

Fig.4a The dependence of flame temperature on equivalence ratio for DME/air mixtures at pressures of $1,1.5,2,4$, and 20 atm.

Fig. $4 b$ The dependence of flame speeds on equivalence ratio for DME/air mixtures at different pressures.

Fig. 5 The pressure dependence of flame temperatures and speeds normalized by that at $1 \mathrm{~atm}$, respectively, for hot flame and cool flames on the fuel lean and fuel rich sides for DME/air (Note: the normalized flame temperature of the rich cool flame overlaps with that of hot flame).

Fig. 6 Flame structure of the high pressure lean cool flame for DME/air mixture at $\Phi=0.2$ and $\mathrm{P}=20 \mathrm{~atm}$

Fig.7 Lean cool flame speed sensitivities to elementary reactions at $\Phi=0.2$ for $P=1$ and 20 atm

Fig.8 A K-shaped flammability limit diagram for cool and hot flames at elevated pressure.

Fig.9 The effect of flame size on the flame temperature and the flammable region of cool flames

Fig.10a The effect of flame size on the transition limit of cool flame to hot flame $\left(\Phi_{\mathrm{E}}\right)$ and the flame speed at the transition limit.

Fig.10b The dependence of normalized cool flame speeds on the upstream computation domain size, respectively, for Case I: lean cool flame at $\Phi=0.19$ and 2 atm; Case II: lean cool flame at $\Phi=0.03$ and 20 atm; and rich cool flame $\Phi=10$ and 20 atm

Fig.10c Comparisons of the volumetric chemical heat release and heat conduction balances for cool flames at three different cases corresponding to Fig.10b: Case I: lean cool flame at $\Phi=0.19$ and 2 atm; Case II: lean cool flame at $\Phi=0.03$ and 20 atm; and rich cool flame $\Phi=10$ and $20 \mathrm{~atm}$

Fig.11a The effect of radiation heat loss intensity on the transition limit of cool flame to hot flame. Here the radiation factor is raised from 1 to 5.

Fig.11b The dependence of cool flame temperature and flame speed on the initial mixture temperature at equivalence ratio of 0.19 and pressure of 2 atm.

Fig. 12(a): Comparison of flame temperature and burning limits between DME/air and $\mathrm{DME} /\left(0.1 \mathrm{O}_{2}+0.9 \mathrm{~N}_{2}\right)$ mixtures. (b): Comparison of flame speeds. 


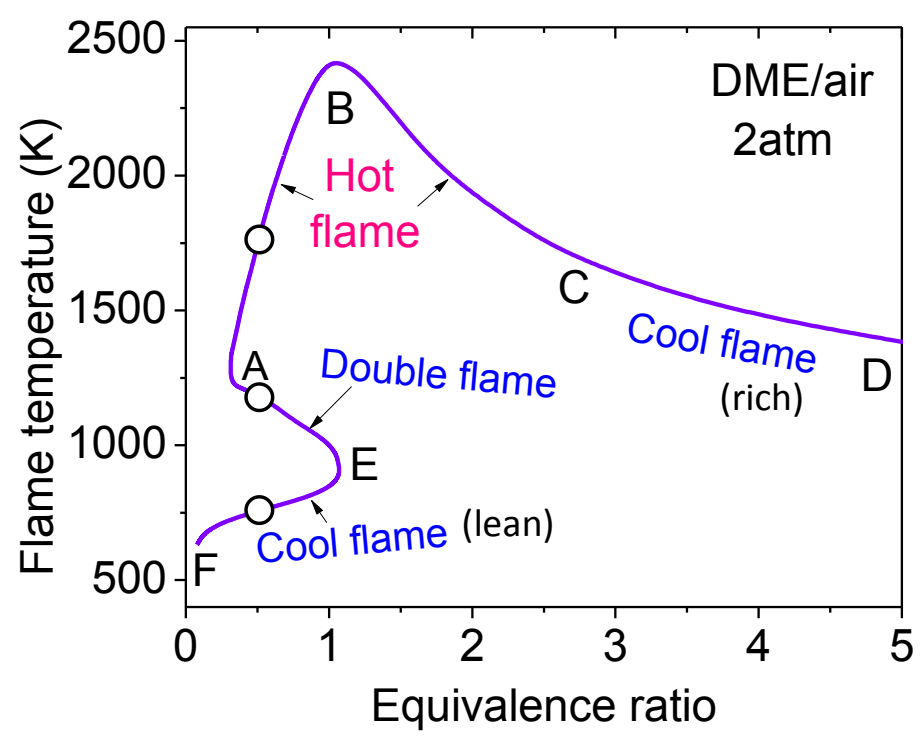

Fig.1 The dependence of flame temperature on equivalence ratio of dimethyl ether/air mixture at $2 \mathrm{~atm}$. The circles mark three different flame regimes at the same condition.
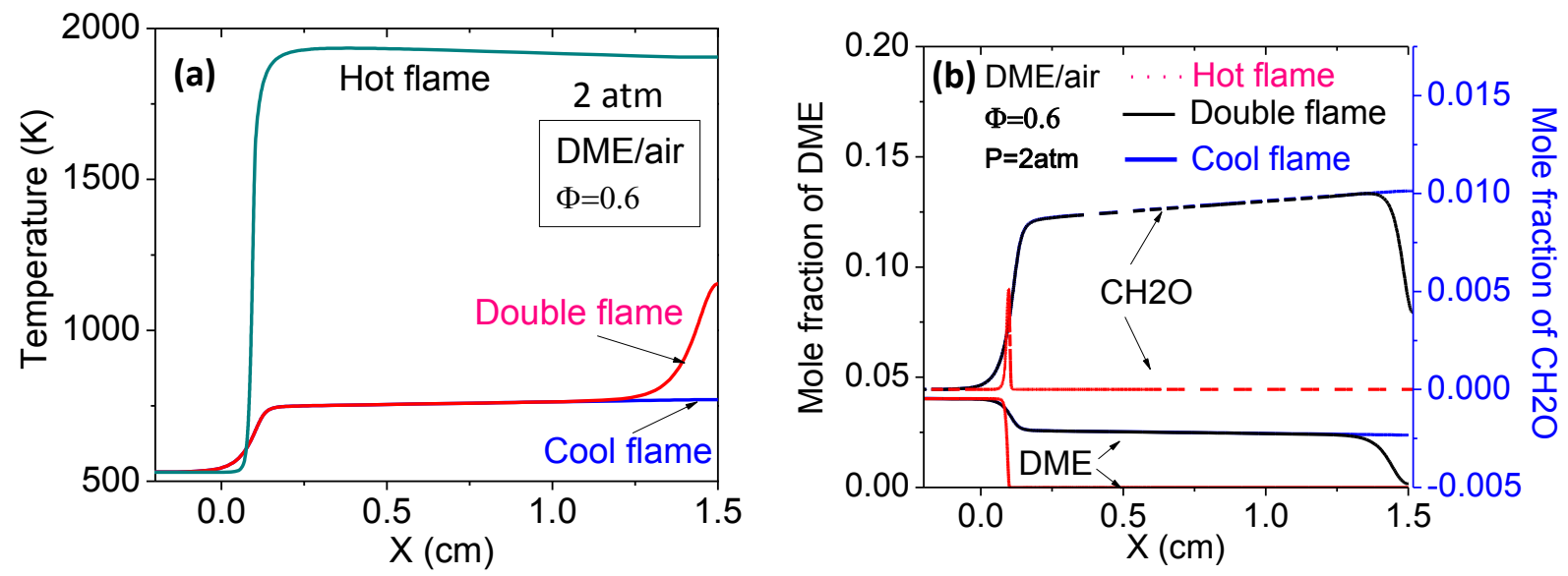

Fig.2 (a) The temperature distribution in the hot flame, double flame, and cool flame, for DME/air mixture at $\Phi=0.6$ and $\mathrm{P}=2$ atm; (b) $\mathrm{CH}_{2} \mathrm{O}$ and DME distributions in the hot flame, double flame, and cool flame, for DME/air mixture at $\Phi=0.6$ and $\mathrm{P}=2$ atm 


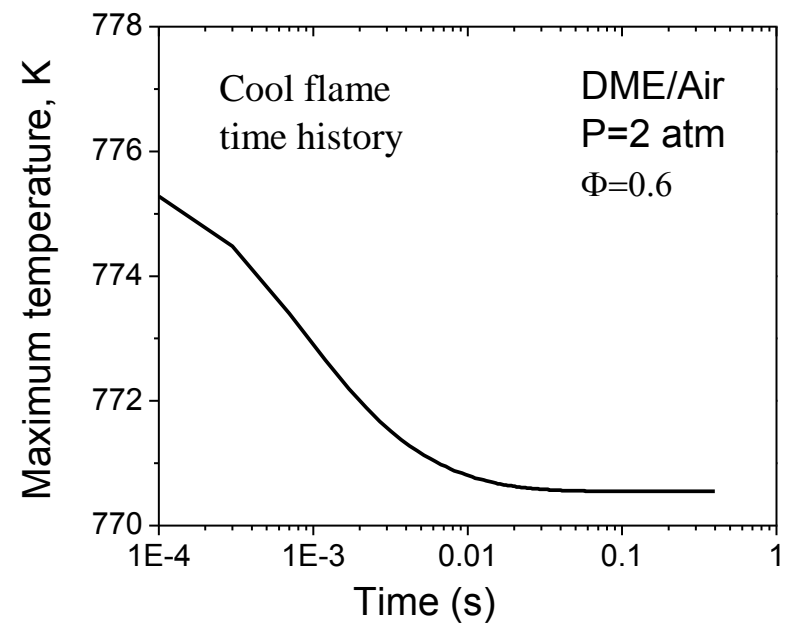

Fig.2c The time history of the peak flame temperature of the lean cool flame at $\Phi=0.6$ and 2 atm with an initial temperature perturbation of $5 \mathrm{~K}$ from the steady state solution.
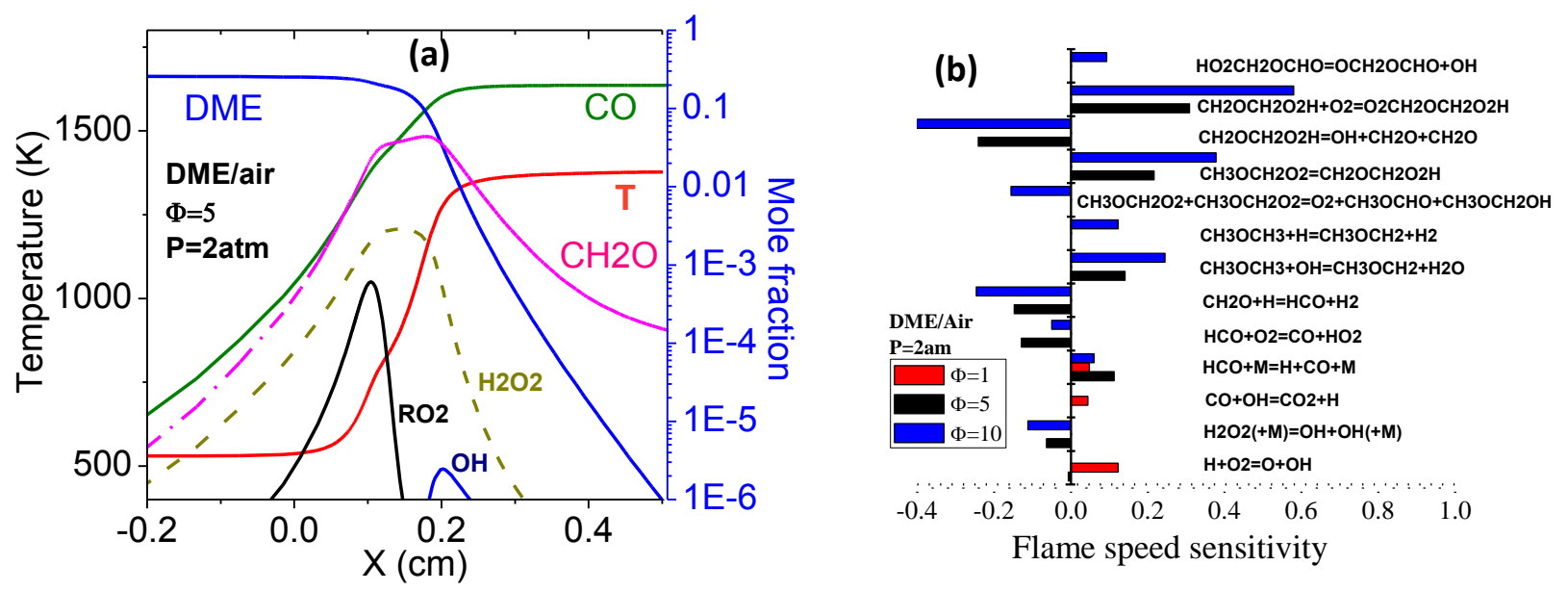

Fig.3 a) Fuel rich flame structure at equivalence ratio of 5; b) Flame speed sensitivity of flames at equivalence ratios of 1,5 , and 10 , respectively. 


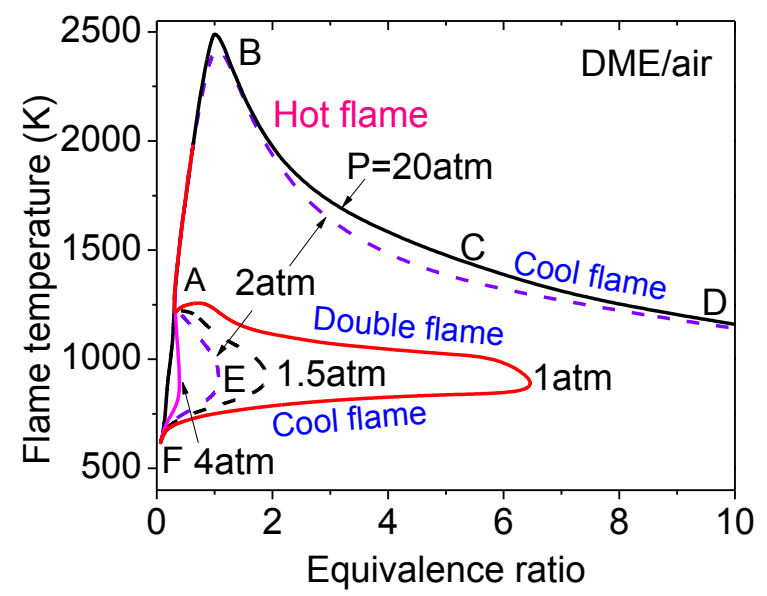

Fig.4a The dependence of flame temperature on equivalence ratio for DME/air mixtures at pressures of 1, 1.5, 2, 4, and $20 \mathrm{~atm}$.

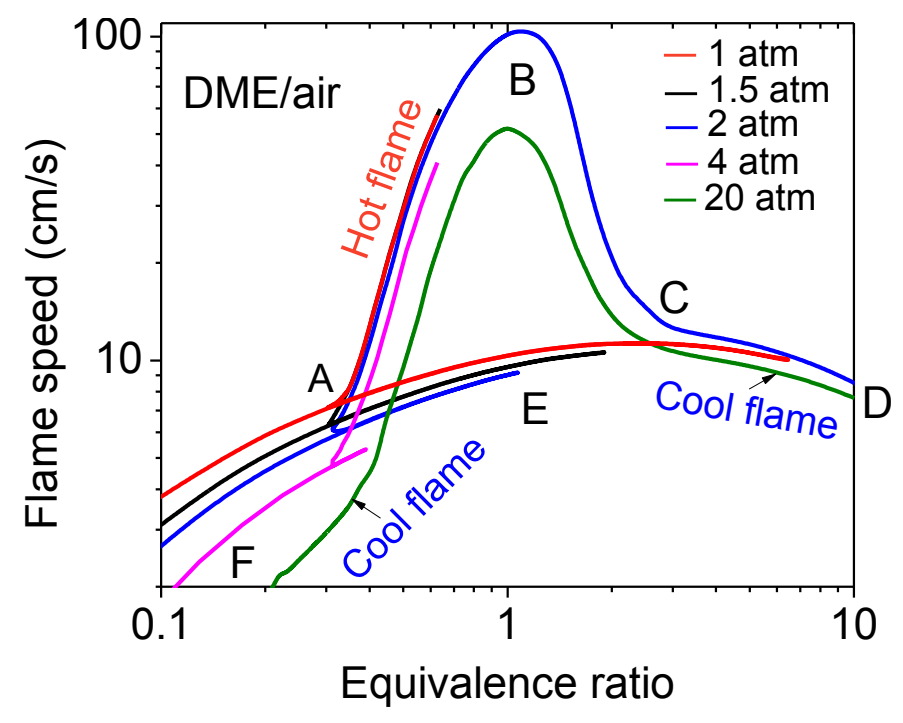

Fig.4b The dependence of flame speeds on equivalence ratio for DME/air mixtures at different pressures. 


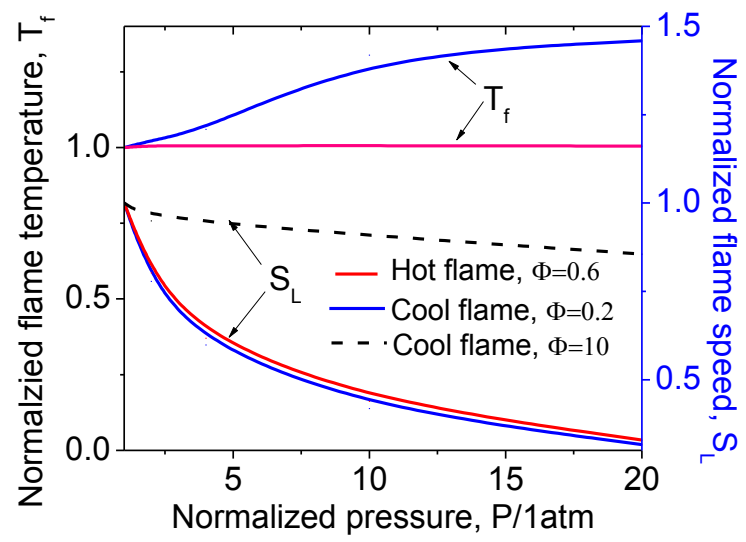

Fig. 5 The pressure dependence of flame temperatures and speeds normalized by that at 1atm, respectively, for hot flame and cool flames on the fuel lean and fuel rich sides for DME/air (Note: the normalized flame temperature of the rich cool flame overlaps with that of hot flame).

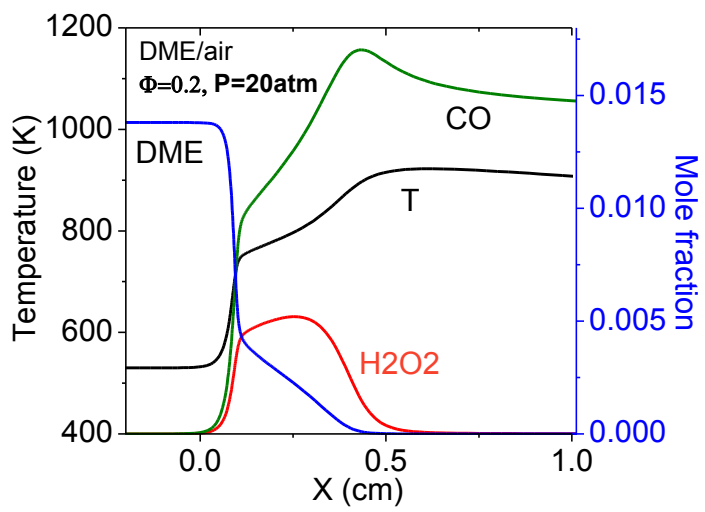

Fig. 6 Flame structure of the high pressure lean cool flame for DME/air mixture at $\Phi=0.2$ and $\mathrm{P}=20 \mathrm{~atm}$ 


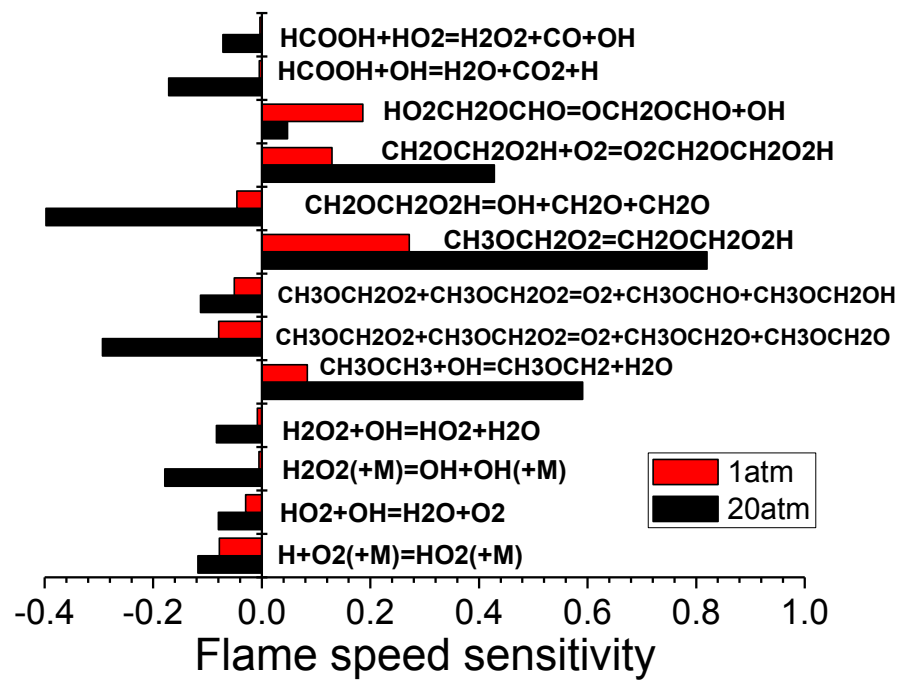

Fig.7 Lean cool flame speed sensitivities to elementary reactions at $\Phi=0.2$ for $\mathrm{P}=1$ and 20 atm

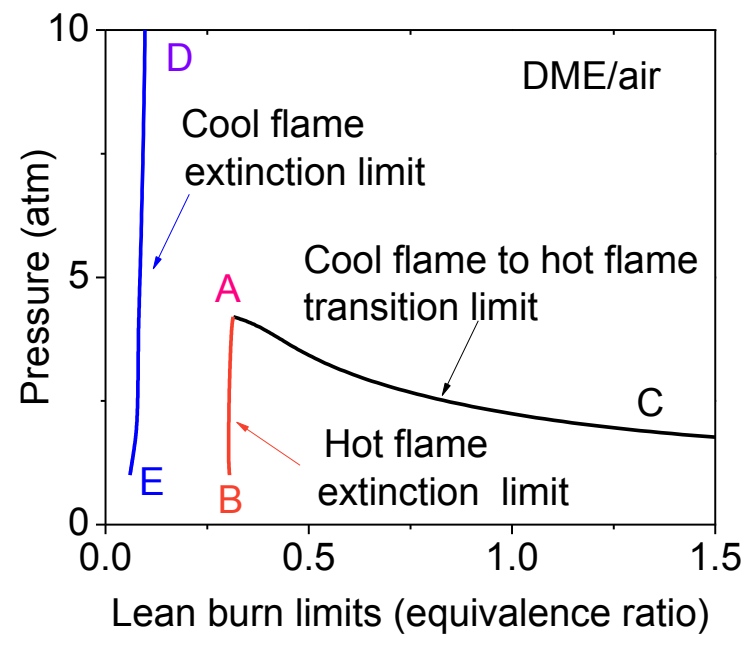

Fig.8 A K-shaped flammability limit diagram for cool and hot flames at elevated pressure. 


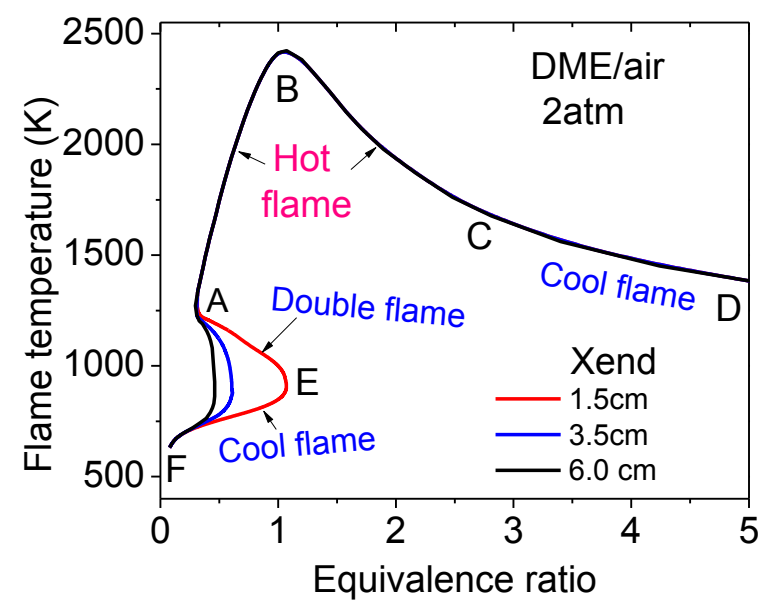

Fig.9 The effect of flame size on the flame temperature and the flammable region of cool flames 


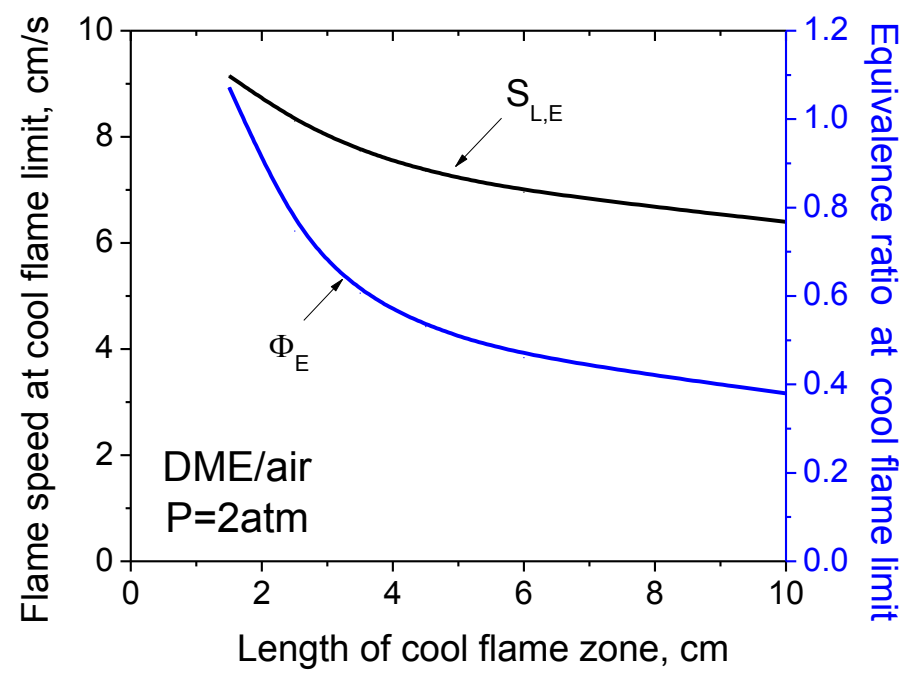

Fig.10a The effect of flame size on the transition limit of cool flame to hot flame $\left(\Phi_{\mathrm{E}}\right)$ and the flame speed at the transition limit.

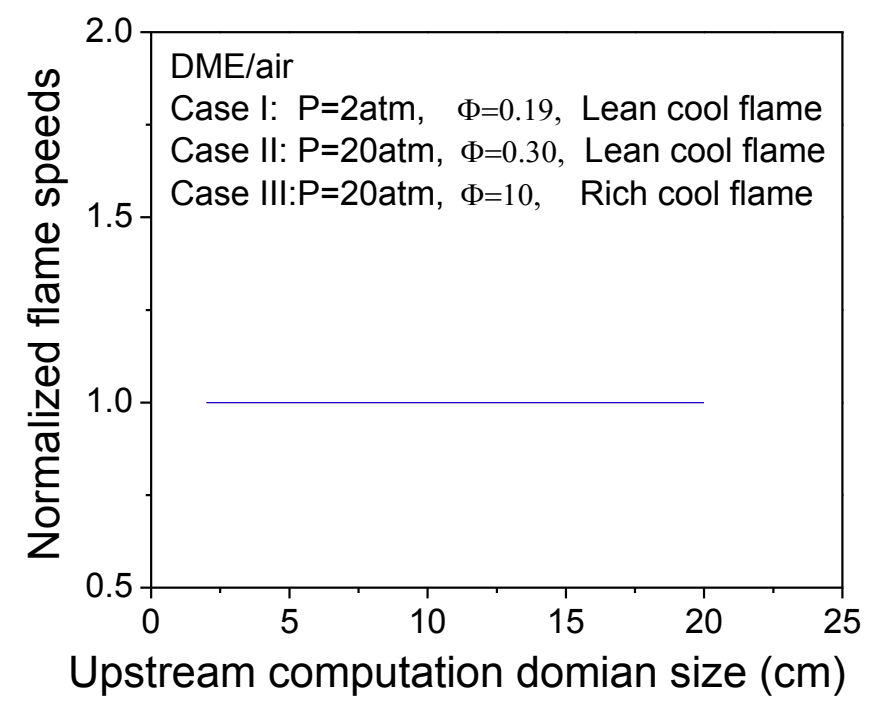

Fig.10b The dependence of normalized cool flame speeds on the upstream computation domain size, respectively, for Case I: lean cool flame at $\Phi=0.19$ and $2 \mathrm{~atm}$; Case II: lean cool flame at $\Phi=0.03$ and $20 \mathrm{~atm}$; and rich cool flame $\Phi=10$ and $20 \mathrm{~atm}$ 

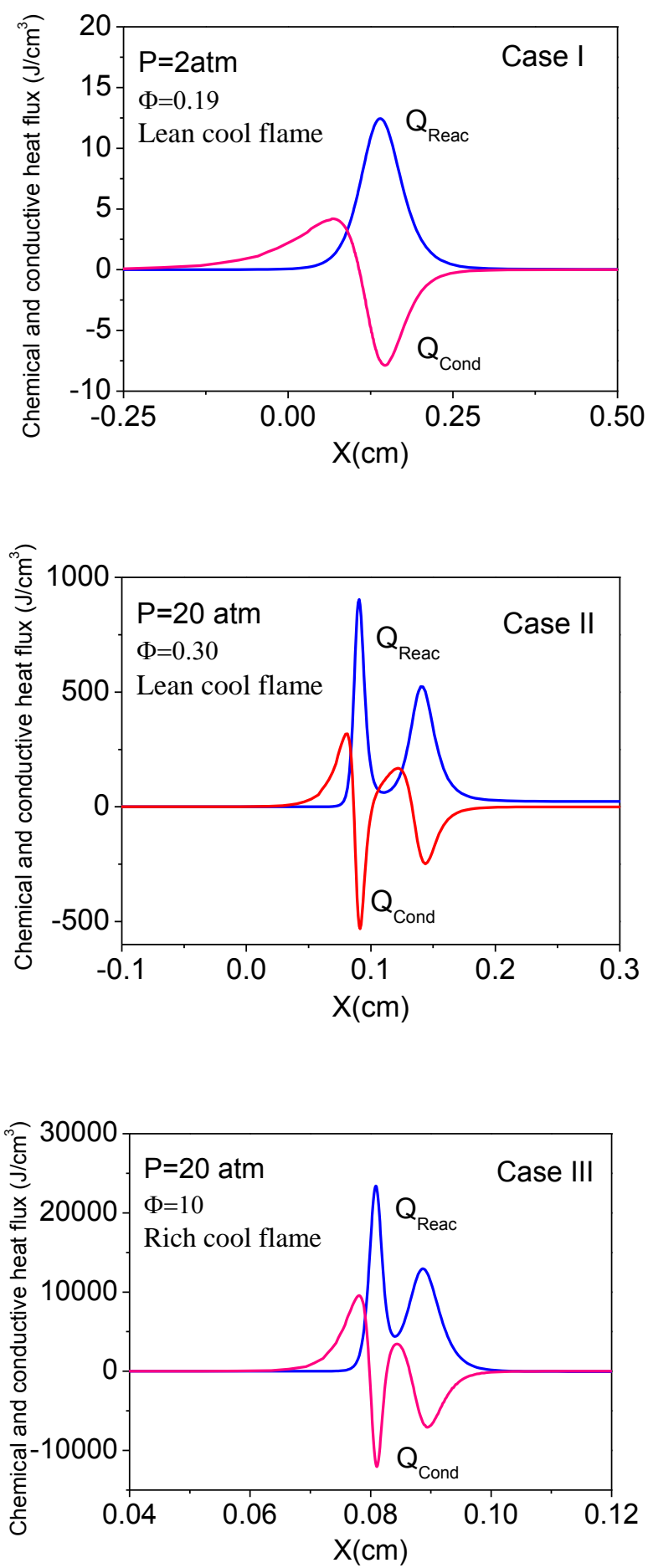

Fig.10c Comparisons of the volumetric chemical heat release and heat conduction balances for cool flames at three different cases corresponding to Fig.10b: Case I: lean cool flame at $\Phi=0.19$ and $2 \mathrm{~atm}$; Case II: lean cool flame at $\Phi=0.03$ and $20 \mathrm{~atm}$; and rich cool flame $\Phi=10$ and $20 \mathrm{~atm}$ 


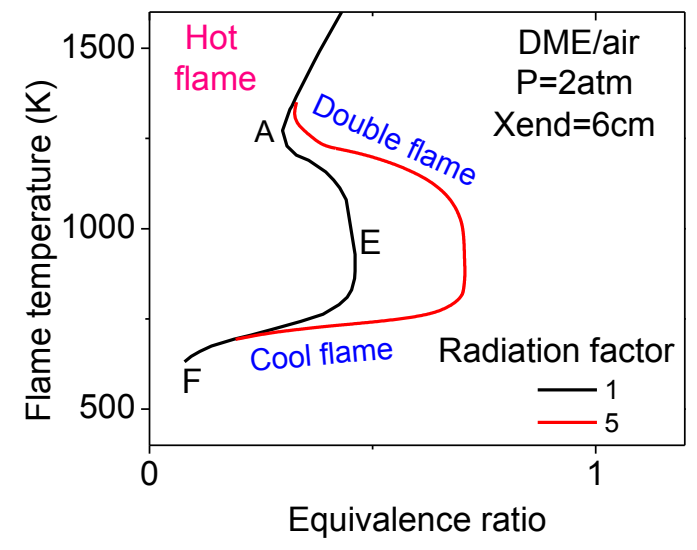

Fig.11a The effect of radiation heat loss intensity on the transition limit of cool flame to hot flame. Here the radiation factor is raised from 1 to 5 .

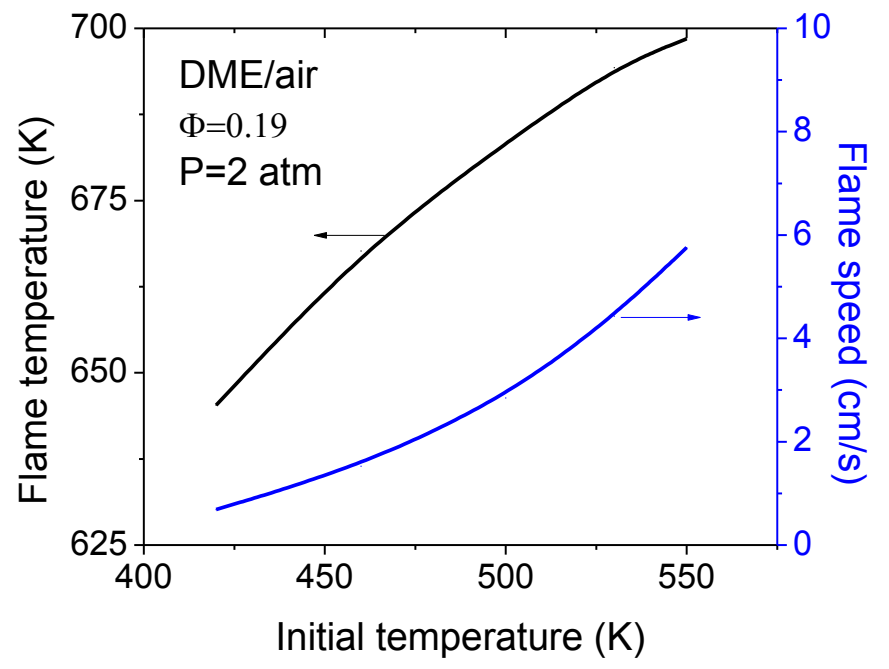

Fig. $11 \mathrm{~b}$ The dependence of cool flame temperature and flame speed on the initial mixture temperature at equivalence ratio of 0.19 and pressure of $2 \mathrm{~atm}$. 

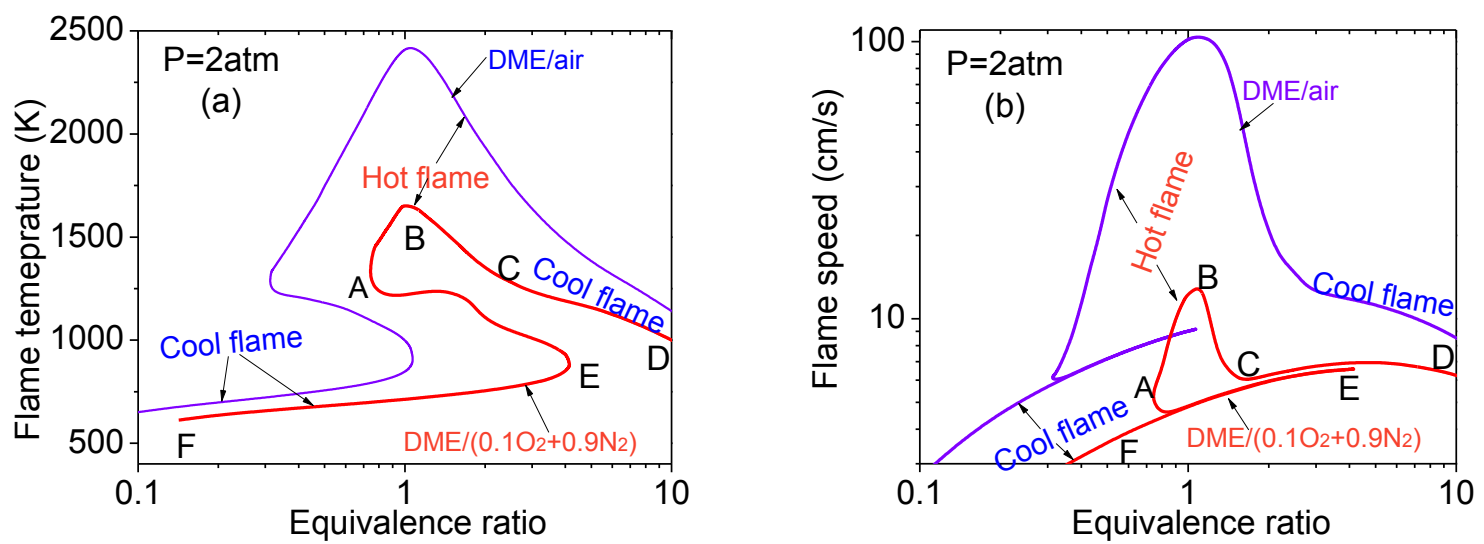

Fig. 12(a): Comparison of flame temperature and burning limits between DME/air and $\mathrm{DME} /\left(0.1 \mathrm{O}_{2}+0.9 \mathrm{~N}_{2}\right)$ mixtures. (b): Comparison of flame speeds. 